\title{
Treatment approaches for interoceptive dysfunctions in drug addiction
}

\author{
Martin P. Paulus ${ }^{1,2}{ }^{*}$, Jennifer L. Stewart ${ }^{1}$ and Lori Haase ${ }^{1}$ \\ 1 Department of Psychiatry, University of California San Diego, La Jolla, CA, USA \\ 2 Psychiatry Service, VA San Diego Healthcare System, La Jolla, CA, USA
}

\author{
Edited by: \\ Antonio Verdejo-García, Universidad \\ de Granada, Spain \\ Reviewed by: \\ Martin Zack, Centre for Addiction and \\ Mental Health, Canada \\ Agnes J. Jasinska, National Institute \\ on Drug Abuse, USA \\ *Correspondence: \\ Martin P. Paulus, Laboratory of \\ Biological Dynamics and Theoretical \\ Medicine, Department of Psychiatry, \\ University of California San Diego, \\ 8939 Villa La Jolla Drive, Suite 200, La \\ Jolla, CA 92037-0985, USA \\ e-mail:mpaulus@ucsd.edu
}

There is emerging evidence that individuals with drug addiction have dysfunctions in brain systems that are important for interoceptive processing, which include, among others, the insular and the anterior cingulate cortices. These individuals may not be expending sufficient neural resources to process perturbations of the interoceptive state but may exert over-activation of these systems when processing drug-related stimuli. As a consequence, insufficient detection and processing of interoceptive state changes may result in inadequate anticipation and preparation to adapt to environmental challenges, e.g., adapt to abstinence in the presence of withdrawal symptoms. Here, we integrate interoceptive dysfunction in drug-addicted individuals, with the neural basis for meditation and exercise to develop a heuristic to target the interoceptive system as potential treatments for drug addiction. First, it is suggested that mindfulness-based approaches can modulate both interoceptive function and insular activation patterns. Second, there is an emerging literature showing that the regulation of physical exercise in the brain involves the insula and anterior cingulate cortex and that intense physical exercise is associated with a insula changes that may provide a window to attenuate the increased interoceptive response to drug-related stimuli. It is concluded that the conceptual framework of interoceptive dysfunctions in drug addiction and the experimental findings in meditation and exercise provide a useful approach to develop new interventions for drug addiction.

Keywords: addiction, interoception, exercise, meditation, insula

\section{INTEROCEPTIVE DYSFUNCTION IN DRUG ADDICTION}

Interoception comprises receiving, processing, and integrating body-relevant signals together with external stimuli to affect motivated behavior $(1,2)$. This process fundamentally affects the degree to which individuals approach or avoid drugs of abuse (3). Different conceptualizations of interoception have included its definition as the state of the individual at a particular point in time (4), or as the sensing of body-related information in terms of awareness (5), sensitivity (6), or accuracy of the sensing process (7). Interoception provides an anatomical framework for identifying pathways focused on modulating the internal state of the individual. This framework comprises peripheral receptors (7), c-fiber afferents, spino-thalamic projections, specific thalamic nuclei, posterior and anterior insula as the limbic sensory cortex, and anterior cingulate cortex (ACC) as the limbic motor cortex [for reviews, see Ref. $(8,9)$ ]. Central to the concept of interoception is that body-state relevant signals comprise a rich and highly organized source of information that affects how an individual engages in motivated behavior. Importantly, interoception is linked to homeostasis (10), which implies that an individual's motivated approach or avoidance behavior toward stimuli and resources in the outside world is aimed at maintaining an equilibrium. For example, a person will approach a heat source in a cold environment but will avoid it when the ambient temperature is high.
The insular cortex is a complex brain structure, which is organized macroscopically along an anterior-posterior (1) and superior-inferior axis (11) and microscopically as granular, dysgranular, and agranular from posterior to anterior insula, respectively $(12,13)$. The anterior cluster is predominately activated by effortful cognitive processing, whereas the posterior region is mostly activated by interoception, perception, and emotion (14). Moreover, the anterior insula, potentially together with the ACC, appears to pivotally influence the dynamics between default-mode and executive control networks (15). The insula is thought to be the central nervous system hub for interoceptive processing such that somatosensory relevant afferents enter the posterior insula and are integrated with the internal state in the mid-insula, and re-represented as complex feeling states within the anterior insular cortex. Although there has been some debate, a recent metaanalysis suggests that the anterior insula is critical and necessary for emotional awareness (16).

The ACC has been labeled the limbic motor cortex by some (9) for review, see Ref. (17), and is thought to be the critical interface between cognitive and emotion processing (18). In particular, Von Economo neurons, which are projection neurons located in layer $\mathrm{V}$ within the ACC and frontoinsular cortex, have been implicated in the integrative function of the ACC (19). However, whether different parts of the ACC are involved in distinct processes and whether these processes are segregated for different functions is still highly 
debated. On the one hand, several investigators have proposed an anatomically based topography of the ACC consisting of subgenual, pregenual, and anterior mid-cingulate cortex, which are cytoarchitecturally distinct and have different connectivity with other brain structures (20). In particular, whereas the rostral ACC (comprising both sub- and pregenual ACC) is important for emotional processing, the dorsal or mid-cingulate cortex is thought to implement cognitive control and emotion regulation (21). However, there is also considerable overlap between the "cognitive" division of the ACC and the mid-cingulate area that processes pain and fear (20). This overlap is consistent with the idea that dorsal-caudal regions of the ACC and medial prefrontal cortex are involved in appraisal and expression of negative emotion (22). On the other hand, based on a meta-analysis of imaging studies, some investigators have proposed that negative affect, pain, and cognitive control activate an overlapping region within the anterior mid-cingulate cortex, which can be thought of as a hub that links reinforcers to motor centers responsible for expressing affect and executing goal-directed behavior (23). In particular, it has been proposed that the ACC supports the selection and maintenance of extended, context-specific sequences of behavior directed toward particular goals that are learned through a process of hierarchical reinforcement learning (24). This generalized view of ACC functioning is consistent with the proposal that this structure, among other functions, orchestrates approach or avoidance behaviors in response to particular internal body states that involve homeostatic perturbations (25). This function of the ACC is supported by the strong functional (26) and anatomical (27) connections between the anterior insula and the ACC. This systemic view is also aligned with a prediction error based conceptualization of the specific computational processes that may be carried out within this structure. For example, a special population of neurons in the ACC seems to fire with positive and negative value information during the decision phase using a unified encoding scheme, which is based on reward prediction errors (28). Others have argued that the ACC encodes salient prediction errors for appetitive and aversive stimuli (29). Finally, activation in the rostral ACC correlates with a belief-based prediction error, which is driven by the discrepancy between the anticipation and action of others (30). Taken together, the ACC receives information about the individual's current state as well as the expected state, and computes various types of error signals that help to establish the selection of an action that is optimally adapted to the higher order goal state.

We have previously hypothesized that individuals who are at risk for drug addiction or who have developed addiction show altered interoceptive processing (31). In particular, individuals who show attenuated processing of internal body states may be at higher risk for substance dependence because these individuals are not able to utilize "body states" to guide their decision-making (32). There has been some evidence that neural substrates processing body-relevant information and their associated neural circuits play an important role in drug addiction $(33,34)$. Individuals take substances to feel better or to avoid feeling worse. The positive and negative reinforcing aspects of drugs of abuse have given rise to a tremendous insight into the behavioral processes $(35,36)$, neural systems $(37,38)$, and molecular mechanisms $(39,40)$ of drug addiction. In comparison, the interoceptive framework is much less developed and needs further empirical validation. We have conceptualized that an individual's motivation to approach or avoid a stimulus, including drugs of abuse, results from a brain-generated body prediction error $(31,41-43)$, i.e., the difference between the experienced and the expected internal state of the individual. In particular, we have argued more recently that optimal behavior emerges from a computational process involving probabilistic representation of belief states in the context of partially observable Markov decision processes (44). In this context, body prediction error is evaluated within the context of the individual's belief about external stimuli and their relevance for specific outcomes. For example, when considering a choice of engaging in risky behavior, individuals with substance use disorders may not appropriately engage the insular cortex to signal the potential aversive outcome. On the other hand, seeing a cue that has previously been associated with drug-taking behavior may generate a large insula response and provide overwhelming approach behavior manifested in cravings and the urge to use.

There is emerging evidence of insula dysfunction across different groups of substance dependent individuals. Yet, it is important to not engage in excessive inverse inference and conclude that because there is evidence for insula dysfunction, this dysfunction extends to interoceptive processing. It is more likely that interoception is one among various processes that are altered in these populations. Specifically, exposure to nicotine-related stimuli increases blood flow in a large network, including the insular cortex (45) and smokers when not smoking (46) and when anticipating to smoke (47) show greater anterior insula activation. In addition, recently abstinent smokers who were more likely to relapse also showed greater insula and ACC activation to smoking-related images (48). Finally, smokers with higher levels of nicotine dependence showed enhanced insula reactivity to smoking-related pictures (49). Similarly, acute administration of cannabis increases blood flow (50) and functional magnetic resonance imaging (fMRI) perfusion signal $(51,52)$ in the insula. Several fMRI studies demonstrate that cannabis users exhibit less activation in the insula during inhibitory processing (53), which has been linked to reduced error awareness (54) but, in contrast, show enhanced insular response to cannabis-related cues (55). In amphetamine users, fMRI studies show attenuated insula activation in cognitive control (56) and emotion processing tasks (57) but enhanced response to pharmacological agents, such as modafinil, aimed at increasing cognitive control (58). Moreover, within an amphetamine dependent sample, attenuated insula activation during a simple decision-making task was associated with increased propensity for relapse (59). Similar to amphetamine, there is evidence for dysfunctional insula in cocaine dependent individuals. fMRI research demonstrates attenuated insula activation during an inhibitory task (60) but enhanced insula response in other tasks such as those involving monetary reward-related processing (61), stress-related imagery (62), presentation of cocaine-related cues (63), which is related to the degree of craving $(64,65)$. This altered insula reactivity in these individuals may undergo dynamic changes as a function of sobriety, e.g., longer periods of abstinence in cocaine dependent subjects relative to those with fewer days of sobriety showed attenuated insula responses during errors on a cognitive control task (66). Considering the different substance dependent populations, 
there is consensus that insula reactivity is reduced during cognitive control tasks but enhanced when individuals are exposed to cues or processes involving reward. This view is consistent with that expressed by Garavan (67), who stated that "drug craving may be an example of the anterior insula's role in interoception and subjective feeling states," which is influenced by changes in general internal states such as satiety (68) as well as top-down cognitive modulation. Moreover, these findings are consistent with the notion that cue reactivity involves a significant visceral component and an urge to act to acquire the drug. In summary, insula dysfunction and altered interoceptive processing consisting of either attenuated processing of non-drug stimuli and excessive processing of drug-related stimuli is emerging as an important pathological process in addiction $(33,69)$.

\section{MODULATING INTEROCEPTIVE SYSTEMS}

There are several possible approaches to modulate how an individual processes and integrates afferent sensing from the inside of the body. The basic proposition is that altering these processes will affect the way an individual processes drug-related cues due to their significant effect on the body state. Here, we will focus on two strategies, that have been used and for which there is some empirical evidence for their efficacy in treating drug addiction. First, we will discuss mindfulness approaches, which are aimed at creating a non-judgmental awareness of the experiences within the body as a function of events that take place in the person's life. Second, we will briefly review the role of physical exercise, which creates an acute bottom up perturbation of interoceptive processing.

\section{MINDFULNESS APPROACHES}

Mindfulness is "the awareness that emerges through paying attention on purpose, in the present moment, and non-judgmentally to the unfolding of experience moment by moment" (70). Mindful awareness is cultivated by providing guided instruction in mindfulness meditation practices including breath-focused attention and body-scanning of sensory experiences. Mindfulness-based techniques, and in particular, mindfulness-based stress reduction (MBSR) developed by Jon Kabat-Zinn $(71,72)$, have been shown to reduce stress-related sequelae (e.g., self-reported stress, medical symptoms, neuroendocrine changes) associated with chronic mental health disorders [e.g., Ref. $(73,74)]$, medical conditions [e.g., Ref. $(75,76)]$, and non-clinical populations [e.g., Ref. (7779)]. As part of mindfulness training, individuals are trained to focus their attention and are instructed to return their attention to their focus point when they become distracted. Thus, it is not surprising that individuals who undergo meditation training show improved attention processing (80-83). There is converging evidence that anatomical (84-87) and functional (88-93) brain changes are associated with mindfulness training, particularly in the insula, ACC, and other brain structures such as the prefrontal cortex. In particular, during pain stimulation, experienced meditators show an increased reactivity consisting of low baseline activity coupled with high response in the anterior insula, which was related to accelerated habituation within the amygdala (94). Experienced meditators also show greater gray matter concentration in the anterior insula (86), which may be the consequence of attention-related adaptation. Others have shown that degree of mindfulness training was related to more efficient pain processing (93), greater inhibitory control (95), greater interoceptive attention in anterior dysgranular insula, as well as altered functional connectivity between posterior insula and dorsomedial prefrontal cortex (96). Taken together, training involving attention modulation and interoception increases the efficiency of the insula and associated neural systems when processing afferent information.

A growing literature suggests that mindfulness-based approaches for the treatment of substance use disorders may be able to reduce the susceptibility to relapse. From a mechanistic perspective, these approaches are intended to increase discriminative awareness, with a specific focus on acceptance of uncomfortable states or challenging situations without reacting with habitual affect (97). There is a small number of well-designed clinical trials and experimental laboratory studies of mindfulness approaches in smoking, alcohol dependence, and illicit substance use (98). For example, meditation has been used as an effective adjunctive therapy for relapse prevention in alcohol dependence (99), smoking cessation (100), and a diverse group of substance dependent individuals (101). In these trials, individuals participating in mindfulness-based interventions demonstrated significantly lower rates of substance use and greater decreases in baseline and negative affect-induced craving (97).

Despite the evidence for the clinical efficacy of mindfulnessbased methods, the specificity of the underlying cognitive and neural mechanisms is still unclear (102). For example, increased levels of mindfulness were associated with lower alcohol attentional bias, stress, and craving, as well as greater alcohol-related self-efficacy (103). Neuroimaging studies indicate greater dorsolateral prefrontal cortex responses during executive processing (95) and decoupling of functional connectivity between subgenual ACC and insula when viewing craving-inducing stimuli such as smoking pictures (104). Finally, there is evidence that cueelicited high-frequency heart rate variability may be modulated by mindfulness and may function as a peripheral marker for relapse susceptibility (105). On the whole, the effect of mindfulness appears to involve brain systems that are important for interoceptive processing in general, and relapse in particular, and alters peripheral markers that have been associated with interoceptive processing. Specifically, mindfulness may enhance one's ability to adequately process body-state relevant information, i.e., improve insula recruitment when experiencing changes in interoceptive afferents, without having to select actions, i.e., engage the ACC to recruit approach or avoidance behaviors. The relative "disconnect" between sensing and acting might result in short-term relief such that following mindfulness intervention, an individual may be able to recognize feelings of craving without acting on them. In other words, the disengagement of motivated action as a result of interoceptive perturbation may enable the individual to learn new actions and not engage in habitual drug use behavior.

\section{EXERCISE}

There is a growing interest in understanding the neural processes underlying physical exercise in general and its role in optimizing levels of physical performance. Several investigators have begun to delineate which brain processes contribute to athletic performance $(106,107)$. The insular cortex has been identified as a component 
of the so-called "central governor," i.e., the brain systems that are important for modulating the degree to which individuals engage in demanding athletic performance (106, 108). Specifically, increased insular regional cerebral blood flow (rCBF) was observed during active, but not passive, cycling (109). Furthermore, both the insula and ACC were also found to activate during imagined exercise (110). Finally, greater insular rCBF was positively correlated with levels of perceived cycling intensity (111) and with individual blood pressure changes.

The central governor model is a conceptual approach to determine how interoceptive afferents influence levels of performance. In particular, the model focuses on perceived exertion (112), i.e., the subjective perception of exercise intensity, as a function of ongoing exercise (113). Recently this model has been extended (114) to include a system of simultaneous efferent feed-forward and afferent feedback signals that are thought to optimize performance by overcoming fatigue through permitting continuous compensation for unexpected peripheral events (115). Afferent information from various physiological systems and external or environmental cues at the onset of exercise can be used to forecast the duration of exercise within homeostatic regulatory limits. This enables individuals to terminate the exercise when the maximal tolerable perceived exertion is attained. In this model, the brain creates a dynamic representation of an expected exertion against which the experienced exertion can be continuously compared (114) to prevent exertion from exceeding acceptable levels. Moreover, the notion of a differential between expected and experienced exertion parallels our model of the body prediction error (42). For example, an athlete may utilize the experience of heavy breathing or heart rate to adjust effort in the presence of external stimuli signaling an upcoming increase in demand. However, Marcora and colleagues have argued that perceived exertion is generated by a top-down or feed-forward signal (107), i.e., the brain - not the body - generates the sense of exertion and proposed that the a centrally generated corollary discharge of the brain is critical for optimal effort (116). Moreover, it has been argued that mental fatigue affects performance via altered perception of effort rather than afferent and body originating cardiorespiratory and musculoenergetic mechanisms (117). In summary, it is most likely the brain, not the body, that sets the subjective level of perceived exertion as a consequence of an interaction between feed-forward (expectations) and feedback (body-relevant sensing) information, which maintains a homeostatic state for the individual to be resilient to physical perturbations. This theoretical formulation is analogous to the perturbation experienced by a drug dependent individual when experiencing craving due to conditioned stimuli that predict availability of drug.

There is an emerging literature on the efficacy and mechanisms of exercise in substance dependent individuals. As recently reviewed in (118), the beneficial effects of exercise as an adjunct in treatment of substance use disorders may be due to its ability to facilitate dopaminergic transmission, normalize glutamatergic and dopaminergic signaling, and reverse drug-induced changes in chromatin via epigenetic interactions with brain-derived neurotrophic factor (BDNF) in the reward pathway (118). Acute exercise reduces alcohol urges (119), cigarette cravings (120,121), and daily cannabis use (122). Neuroimaging studies have shown that relative to a resting condition, individuals undergoing exercise showed reduced desire to smoke and attenuated brain activation in limbic areas in response to smoking-related stimuli (120) and an accompanying increase in default-mode activation (123). However, the precise cognitive and neural mechanisms that contribute to the beneficial effects of exercise on drug-taking behavior in individuals with substance use disorder still await further study. One possible hypothesis is that the ACC, via repeated engagement of controlled goal-directed action, is better prepared to respond to body-relevant information that is initiated by drug-relevant stimuli. Thus, in some ways, exercise might also alter cognitive control mechanisms that are important for drug addiction.

\section{NEURAL BASIS OF INTEROCEPTIVE PLASTICITY AND TREATMENT IN DRUG ADDICTION}

Interoception, particularly its dysfunction in individuals with drug addiction, provides a conceptual and neural systems framework as well as various experimental approaches to examine the mechanisms underlying interventions that may be effective in reducing an individual's susceptibility to drug use, cravings associated with exposure to conditioned stimuli, and the ability to select alternative behaviors when anticipating aversive states associated with substance withdrawal. One way to conceptualize the degree of motivated approach/avoidance behavior in the context of drug addiction is to view the emerging behavior as a consequence of a homeostatic adjustment to a body prediction error $(31,41-$ 43), i.e., the difference between the experienced and the expected internal state of the individual. However, the simple difference between an experienced and expected body state does not explain opposing insular cortex effects in different task settings in substance use populations. We have proposed that optimal behavior emerges from a computational process involving probabilistic representation of belief states (44). Here, body prediction error is evaluated within the context of the individual's belief about external stimuli and their relevance for specific outcomes. Specifically, seeing a drug-related cue may generate a large insula response and provide an overwhelming urge to engage in drug seeking behavior. This view of the differential contribution of the interoceptive afferents to motivated behavior is consistent with the multi-modal connections of the insula with other brain areas. These modulatory influences may ultimately determine whether an "embodied" state is (a) amplified and experienced, (b) contributes to ongoing behavior, and (c) becomes a target for the cognitive control system to modulate its influence. This conceptual approach, although based on an interoceptive heuristic, also involves computational processes that are clearly within the realm of cognitive control, e.g., the facilitation or inhibition of competing responses. Thus, this approach is not inconsistent with the notion of cognitive control dysfunctions in addiction $(124,125)$ and should be seen as complementary, i.e., similar to the notion of embodied cognition (126).

Both meditation and exercise can be viewed as systematic approaches to alter the way approach/avoidance behavior emerges from a body prediction error. For example, it appears that elite athletes, which have undergone extensive physical exercise have the ability to use predictive signals to modulate the insula response to an aversive interoceptive perturbation (127). Similarly, others 
have shown that meditation alters the influence of the dorsomedial prefrontal cortex on insula activation in response to an interoceptive awareness task (96). Together, these findings point toward the plasticity of the neural substrates that are important for interoceptive processing. Practically speaking, meditation and exercise may modulate the interoceptive circuitry by altering the way the individual processes stimuli that are predictive of an altered homeostasis, e.g., smoking cues or the emergence of a substance withdrawal state, and enables one to engage in alternative behaviors. Moreover, exercise helps to optimize complex goaldirected behaviors, which may train the ACC to computer more appropriate value signals. Meditative approaches highlight the influence of pre-existing belief systems on the evaluation of conditioned stimuli and may thereby alter the computational process

\section{REFERENCES}

1. Craig AD. How do you feel? Interoception: the sense of the physiological condition of the body. Nat Rev Neurosci (2002) 3:655-66. doi:10.1038/nrn894

2. Craig AD. How do you feel now? The anterior insula and human awareness. Nat Rev Neurosci (2009) 10:59-70. doi:10. 1038/nrn2555

3. Paulus MP, Stewart JL. Interoception and drug addiction. $\mathrm{Neu}$ ropharmacology (2013). doi:10. 1016/j.neuropharm.2013.07.002

4. Craig AD. The sentient self. Brain Struct Funct (2010) 214: 563-77. doi:10.1007/s00429-0100248-y

5. Pollatos O, Kirsch W, Schandry R. On the relationship between interoceptive awareness, emotional experience, and brain processes. Brain Res Cogn Brain Res (2005) 25:948-62. doi:10. 1016/j.cogbrainres.2005.09.019

6. Holzl R, Erasmus LP, Moltner A. Detection, discrimination and sensation of visceral stimuli. Biol Psychol (1996) 42:199-214. doi:10. 1016/0301-0511(95)05155-4

7. Vaitl D. Interoception. Biol Psychol (1996) 42:1-27. doi:10.1016/03010511(95)05144-9

8. Augustine JR. Circuitry and functional aspects of the insular lobe in primates including humans. Brain Res Brain Res Rev (1996) 22:229-44. doi:10.1016/S01650173(96)00011-2

9. Craig AD. Interoception and emotion: a neuroanatomical perspective. In: Lewis $\mathrm{M}$, HavilandJones JM, Feldman Barrett L editors. Handbook of Emotions. New York: Guilford Press (2007). p. 272-90.

10. Craig AD. Interoception: the sense of the physiological condition of the body. Curr Opin Neurobiol
(2003) 13:500-5. doi:10.1016/ S0959-4388(03)00090-4 AR, Eickhoff SB. A link between the systems: functional differentiation and integration within the human insula revealed by metaanalysis. Brain Struct Funct (2010) 214:519-34. doi:10.1007/s00429010-0255-z

12. Shipp S. The importance of being agranular: a comparative account of visual and motor cortex. Philos Trans $R$ Soc Lond B Biol Sci (2005) 360:797-814. doi:10.1098/ rstb.2005.1630

13. Chikama M, McFarland NR, Amaral DG, Haber SN. Insular cortical projections to functional regions of the striatum correlate with cortical cytoarchitectonic organization in the primate. J Neurosci (1997) 17:9686-705.

14. Cauda F, Costa T, Torta DM, Sacco K, D'Agata F, Duca S, et al. Metaanalytic clustering of the insular cortex: characterizing the metaanalytic connectivity of the insula when involved in active tasks. Neuroimage (2012) 62:343-55. doi:10. 1016/j.neuroimage.2012.04.012

15. Sutherland MT, McHugh MJ, Pariyadath V, Stein EA. Resting state functional connectivity in addiction: lessons learned and a road ahead. Neuroimage (2012) 62:2281-95. doi:10.1016/j. neuroimage.2012.01.117

16. Gu X, Hof PR, Friston KJ, Fan J. Anterior insular cortex and emotional awareness. J Comp Neurol (2013) 521:3371-88. doi:10.1002/ cne. 23368

17. Allman JM, Hakeem A, Erwin JM, Nimchinsky E, Hof P. The anterior cingulate cortex. The evolution of an interface between emotion and cognition. Ann N Y Acad Sci (2001) 935:107-17. doi:10.1111/j. 1749-6632.2001.tb03476.x
11. Kurth F, Zilles K, Fox PT, Laird

involving probabilistic representation of belief states as proposed previously (44). Practically, this may optimize behavioral choices in the context of goal states that are associated with an immediate reward but long-term aversive consequences. Nevertheless, future experimental approaches will need to examine whether this conceptualization adequately describes the restricted behavioral repertoire observed in individuals with substance use disorders. Finally, many open questions remain regarding the mechanisms of meditation and exercise on the neural systems that are important for recovery from substance use disorders. Overall, the conceptual framework of interoceptive dysfunctions in drug addiction and the experimental findings in meditation and exercise provide a useful approach to use neuroscience to develop new interventions for drug addiction.

18. Vogt BA, Berger GR, Derbyshire SW. Structural and functional dichotomy of human midcingulate cortex. Eur J Neurosci (2003) 18:3134-44. doi:10.1111/j. 1460-9568.2003.03034.x

19. Butti C, Santos M, Uppal N, Hof PR. Von Economo neurons: clinical and evolutionary perspectives. Cortex (2013) 49:312-26. doi:10. 1016/j.cortex.2011.10.004

20. Vogt BA. Pain and emotion interactions in subregions of the cingulate gyrus. Nat Rev Neurosci (2005) 6:533-44. doi:10.1038/ nrn1704

21. Mohanty A, Engels AS, Herrington JD, Heller W, Ho MH, Banich MT, et al. Differential engagement of anterior cingulate cortex subdivisions for cognitive and emotional function. Psychophysiology (2007) 44:343-51. doi:10.1111/j. 1469-8986.2007.00515.x

22. Etkin A, Egner T, Kalisch R. Emotional processing in anterior cingulate and medial prefrontal cortex. Trends Cogn Sci (2011) 15:85-93. doi:10.1016/j.tics.2010.11.004

23. Shackman AJ, Salomons TV, Slagter HA, Fox AS, Winter JJ, Davidson RJ. The integration of negative affect, pain and cognitive control in the cingulate cortex. Nat Rev Neurosci (2011) 12:154-67. doi:10.1038/nrn2994

24. Holroyd CB, Yeung N. Motivation of extended behaviors by anterior cingulate cortex. Trends Cogn Sci (2012) 16:122-8. doi:10.1016/ j.tics.2011.12.008

25. Weston CS. Another major function of the anterior cingulate cortex: the representation of requirements. Neurosci Biobehav Rev (2012) 36:90-110. doi:10.1016/j. neubiorev.2011.04.014

26. Taylor KS, Seminowicz DA, Davis KD. Two systems of resting state connectivity between the insula and cingulate cortex. Hum Brain Mapp (2009) 30:2731-45. doi:10. 1002/hbm.20705

27. Ongur D, Price JL. The organization of networks within the orbital and medial prefrontal cortex of rats, monkeys and humans. Cereb Cortex (2000) 10:206-19. doi:10. 1093/cercor/10.3.206

28. Wallis JD, Kennerley SW. Contrasting reward signals in the orbitofrontal cortex and anterior cingulate cortex. Ann N Y Acad Sci (2011) 1239:33-42. doi:10.1111/j. 1749-6632.2011.06277.x

29. Metereau E, Dreher JC. Cerebral correlates of salient prediction error for different rewards and punishments. Cereb Cortex (2013) 23:477-87. doi:10.1093/ cercor/bhs 037

30. Zhu L, Mathewson KE, Hsu M. Dissociable neural representations of reinforcement and belief prediction errors underlie strategic learning. Proc Natl Acad Sci U S A (2012) 109:1419-24. doi:10.1073/ pnas.1116783109

31. Paulus MP, Tapert SF, Schulteis $\mathrm{G}$. The role of interoception and alliesthesia in addiction. Pharmacol Biochem Behav (2009) 94:1-7. doi:10.1016/j.pbb.2009.08.005

32. Paulus MP. Decision-making dysfunctions in psychiatry - altered homeostatic processing? Science (2007) 318:602-6. doi:10.1126/ science. 1142997

33. Naqvi NH, Bechara A. The insula and drug addiction: an interoceptive view of pleasure, urges, and decision-making. Brain Struct Funct (2010) 214:435-50. doi:10. 1007/s00429-010-0268-7

34. Naqvi NH, Rudrauf D, Damasio $\mathrm{H}$, Bechara A. Damage to the insula disrupts addiction to cigarette smoking. Science (2007) 315:531-4. doi:10.1126/ science. 1135926 
35. Koob GF, Le Moal M. Drug abuse: hedonic homeostatic dysregulation. Science (1997) 278:52-8. doi: 10.1126/science.278.5335.52

36. Robinson TE, Berridge KC. Addiction. Annu Rev Psychol (2003) 54:25-53. doi:10.1146/annurev. psych.54.101601.145237

37. Everitt BJ, Robbins TW. Neural systems of reinforcement for drug addiction: from actions to habits to compulsion. Nat Neurosci (2005) 8:1481-9. doi:10.1038/nn1579

38. London ED, Ernst M, Grant $\mathrm{S}$, Bonson $\mathrm{K}$, Weinstein $\mathrm{A}$. Orbitofrontal cortex and human drug abuse: functional imaging. Cereb Cortex (2000) 10:334-42. doi:10.1093/cercor/10.3.334

39. Nestler EJ, Aghajanian GK. Molecular and cellular basis of addiction. Science (1997) 278:58-63. doi:10. 1126/science.278.5335.58

40. Kalivas PW, Volkow ND. The neural basis of addiction: a pathology of motivation and choice. Am J Psychiatry (2005) 162:1403-13. doi:10.1176/appi.ajp.162.8.1403

41. Paulus MP, Stein MB. Interoception in anxiety and depression. Brain Struct Funct (2010) 214:451-63. doi:10.1007/s00429010-0258-9

42. Paulus MP, Potterat EG, Taylor MK, Van Orden KF, Bauman J, Momen N, et al. A neuroscience approach to optimizing brain resources for human performance in extreme environments. Neurosci Biobehav Rev (2009) 33:1080-8. doi:10.1016/j. neubiorev.2009.05.003

43. Paulus MP, Stein MB. An insular view of anxiety. Biol Psychiatry (2006) 60:383-7. doi:10.1016/ j.biopsych.2006.03.042

44. Paulus MP, Yu AJ. Emotion and decision-making: affectdriven belief systems in anxiety and depression. Trends Cogn Sci (2012) 16:476-83. doi:10.1016/j.tics.2012.07.009

45. Franklin TR, Wang Z, Wang J, Sciortino N, Harper D, Li Y, et al. Limbic activation to cigarette smoking cues independent of nicotine withdrawal: a perfusion fMRI study. Neuropsychopharmacology (2007) 32:2301-9. doi:10. 1038/sj.npp.1301371

46. Sutherland MT, Ross TJ, Shakleya DM, Huestis MA, Stein EA. Chronic smoking, but not acute nicotine administration, modulates neural correlates of working memory. Psychopharmacology (Berl) (2011) 213:29-42. doi:10. 1007/s00213-010-2013-6
47. Addicott MA, Baranger DA, Kozink RV, Smoski MJ, Dichter GS, McClernon FJ. Smoking withdrawal is associated with increases in brain activation during decision making and reward anticipation: a preliminary study. Psychopharmacology (Berl) (2012) 219:563-73. doi:10.1007/s00213-011-2404-3

48. Janes AC, Pizzagalli DA, Richardt S, Frederick Bde B, Holmes AJ, Sousa J, et al. Neural substrates of attentional bias for smoking-related cues: an FMRI study. Neuropsychopharmacology (2010) 35:2339-45. doi:10.1038/ npp. 2010.103

49. Goudriaan AE, de Ruiter MB, van den Brink W, Oosterlaan J, Veltman DJ. Brain activation patterns associated with cue reactivity and craving in abstinent problem gamblers, heavy smokers and healthy controls: an fMRI study. Addict Biol (2010) 15:491-503. doi:10.1111/j. 1369-1600.2010.00242.x

50. O'Leary DS, Block RI, Flaum M, Schultz SK, Boles Ponto LL, Watkins GL, et al. Acute marijuana effects on rCBF and cognition: a PET study. Neuroreport (2000) 11:3835-41. doi:10.1097/ 00001756-200011270-00047

51. van Hell $\mathrm{HH}$, Bossong $\mathrm{MG}$, Jager G, Kristo G, van Osch MJ, Zelaya F, et al. Evidence for involvement of the insula in the psychotropic effects of THC in humans: a double-blind, randomized pharmacological MRI study. Int J Neuropsychopharmacol (2011) 14:1377-88. doi:10.1017/ S1461145711000526

52. Jacobus J, Goldenberg D, Wierenga CE, Tolentino NJ, Liu TT, Tapert SF. Altered cerebral blood flow and neurocognitive correlates in adolescent cannabis users. Psychopharmacology (Berl) (2012) 222:675-84. doi:10.1007/s00213012-2674-4

53. Hester R, Nestor L, Garavan H. Impaired error awareness and anterior cingulate cortex hypoactivity in chronic cannabis users. Neuropsychopharmacology (2009) 34:2450-8. doi:10.1038/npp.2009. 67

54. Nestor L, Hester R, Garavan H. Increased ventral striatal BOLD activity during non-drug reward anticipation in cannabis users. Neuroimage (2010) 49:1133-43. doi:10.1016/j.neuroimage.2009. 07.022

55. Filbey FM, Schacht JP, Myers US, Chavez RS, Hutchison KE. Marijuana craving in the brain. Proc
Natl Acad Sci U S A (2009) 106:13016-21. doi:10.1073/pnas. 0903863106

56. Nestor LJ, Ghahremani DG, Monterosso J, London ED. Prefrontal hypoactivation during cognitive control in early abstinent methamphetaminedependent subjects. Psychiatry Res (2011) 194:287-95. doi:10.1016/j. pscychresns.2011.04.010

57. Kim YT, Song HJ, Seo JH, Lee JJ, Lee J, Kwon DH, et al. The differences in neural network activity between methamphetamine abusers and healthy subjects performing an emotion-matching task: functional MRI study. NMR Biomed (2011) 24:1392-1400. doi: 10.1002/nbm. 1702

58. Ghahremani DG, Tabibnia G, Monterosso J, Hellemann G, Poldrack RA, London ED. Effect of modafinil on learning and task-related brain activity in methamphetamine-dependent and healthy individuals. Neuropsychopharmacology (2011) 36:950-9. doi:10.1038/npp.2010.233

59. Paulus MP, Tapert SF, Schuckit MA. Neural activation patterns of methamphetamine-dependent subjects during decision making predict relapse. Arch Gen Psychiatry (2005) 62:761-8. doi:10.1001/ archpsyc.62.7.761

60. Kaufman JN, Ross TJ, Stein EA, Garavan H. Cingulate hypoactivity in cocaine users during a GONOGO task as revealed by eventrelated functional magnetic resonance imaging. J Neurosci (2003) 23:7839-43.

61. Jia Z, Worhunsky PD, Carroll KM, Rounsaville BJ, Stevens MC, Pearlson GD, et al. An initial study of neural responses to monetary incentives as related to treatment outcome in cocaine dependence. Biol Psychiatry (2011) 70:553-60. doi:10.1016/j.biopsych.2011.05. 008

62. Li CS, Kosten TR, Sinha R. Sex differences in brain activation during stress imagery in abstinent cocaine users: a functional magnetic resonance imaging study. Biol Psychiatry (2005) 57:487-94. doi:10.1016/ j.biopsych.2004.11.048

63. Bonson KR, Grant SJ, Contoreggi CS, Links JM, Metcalfe J, Weyl HL, et al. Neural systems and cue-induced cocaine craving. Neuropsychopharmacology (2002) 26:376-86. doi:10.1016/S0893133X(01)00371-2

64. Garavan H, Pankiewicz J, Bloom A, Cho JK, Sperry L, Ross TJ, et al.
Cue-induced cocaine craving: neuroanatomical specificity for drug users and drug stimuli. Am J Psychiatry (2000) 157:1789-98. doi: 10.1176/appi.ajp.157.11.1789

65. Kilts CD, Schweitzer JB, Quinn CK, Gross RE, Faber TL, Muhammad F, et al. Neural activity related to drug craving in cocaine addiction. Arch Gen Psychiatry (2001) 58:334-41. doi:10.1001/archpsyc.58.4.334

66. Li CS, Luo X, Sinha R, Rounsaville BJ, Carroll KM, Malison RT, et al. Increased error-related thalamic activity during early compared to late cocaine abstinence. Drug Alcohol Depend (2010) 109:181-9. doi: 10.1016/j.drugalcdep.2010.01.008

67. Garavan H. Insula and drug cravings. Brain Struct Funct (2010) 214:593-601. doi:10.1007/s00429010-0259-8

68. Haase L, Cerf-Ducastel B, Murphy C. Cortical activation in response to pure taste stimuli during the physiological states of hunger and satiety. Neuroimage (2009) 44:1008-21. doi:10.1016/j. neuroimage.2008.09.044

69. Verdejo-Garcia A, Bechara A. A somatic marker theory of addiction. Neuropharmacology (2008) 56(Suppl 1):48-62. doi:10.1016/j. neuropharm.2008.07.035

70. Kabat-Zinn J. Mindfulness-based interventions in context: past, present, and future. Clin Psychol Sci Pract (2003) 10:144-56. doi:10. 1093/clipsy.bpg016

71. Kabat-Zinn J. An outpatient program in behavioral medicine for chronic pain patients based on the practice of mindfulness meditation: theoretical considerations and preliminary results. Gen Hosp Psychiatry (1982) 4:33-47. doi:10. 1016/0163-8343(82)90026-3

72. Kabat-Zinn J. Full Catastrophe Living: Using the Wisdom of your Mind and Body to Face Stress, Pain, And Illness. New York: Delacorte (1990).

73. Hofmann SG, Sawyer AT, Witt AA, Oh D. The effect of mindfulnessbased therapy on anxiety and depression: a meta-analytic review. J Consult Clin Psychol (2010) 78:169-83. doi:10.1037/a0018555

74. Bowen S, Witkiewitz K, Dillworth TM, Chawla N, Simpson TL, Ostafin BD, et al. Mindfulness meditation and substance use in an incarcerated population. Psychol Addict Behav (2006) 20:343-7. doi:10.1037/0893-164X.20.3.343

75. Kabat-Zinn J, Lipworth L, Burney R. The clinical use of mindfulness meditation for the 
self-regulation of chronic pain. $J$ Behav Med (1985) 8:163-90. doi: 10.1007/BF00845519

76. Carlson LE, Speca M, Faris P, Patel KD. One year pre-post intervention follow-up of psychological, immune, endocrine and blood pressure outcomes of mindfulness-based stress reduction (MBSR) in breast and prostate cancer outpatients. Brain Behav Immun (2007) 21:1038-49. doi:10. 1016/j.bbi.2007.04.002

77. Grossman P, Niemann L, Schmidt S, Walach H. Mindfulness-based stress reduction and health benefits. A meta-analysis. J Psychosom Res (2004) 57:35-43. doi:10.1016/ S0022-3999(03)00573-7

78. Chiesa A, Serretti A. Mindfulnessbased stress reduction for stress management in healthy people: a review and metaanalysis. $J$ Altern Complement Med (2009) 15:593-600. doi:10.1089/acm.2008.0495

79. Wolever RQ, Bobinet KJ, McCabe K, MacKenzie ER, Fekete E, Kusnick CA, et al. Effective and viable mind-body stress reduction in the workplace: a randomized controlled trial. J Occup Health Psychol (2012) 17:246-58. doi:10. 1037/a0027278

80. Jha AP, Krompinger J, Baime MJ. Mindfulness training modifies subsystems of attention. Cogn Affect Behav Neurosci (2007) 7:109-19. doi:10.3758/CABN.7.2. 109

81. Jensen CG, Vangkilde S, Frokjaer V, Hasselbalch SG. Mindfulness training affects attention - or is it attentional effort? J Exp Psychol Gen (2012) 141:106-23. doi: 10.1037/a0024931

82. Tang YY, Ma Y, Wang J, Fan Y, Feng S, Lu Q, et al. Short-term meditation training improves attention and self-regulation. Proc Natl Acad Sci U S A (2007) 104:17152-6. doi:10.1073/pnas.0707678104

83. Wenk-Sormaz H. Meditation can reduce habitual responding. $A d v$ Mind Body Med (2005) 21:33-49.

84. Kang DH, Jo HJ, Jung WH, Kim $\mathrm{SH}$, Jung $\mathrm{YH}$, Choi $\mathrm{CH}$, et al. The effect of meditation on brain structure: cortical thickness mapping and diffusion tensor imaging. Soc Cogn Affect Neurosci (2013) 8:27-33. doi:10.1093/scan/nss056

85. Grant JA, Courtemanche J, Duerden EG, Duncan GH, Rainville P. Cortical thickness and pain sensitivity in zen meditators. Emotion (2010) 10:43-53. doi:10.1037/ a0018334
86. Holzel BK, Ott U, Gard T, Hempel $\mathrm{H}$, Weygandt $\mathrm{M}$, Morgen $\mathrm{K}$, et al. Investigation of mindfulness meditation practitioners with voxel-based morphometry. Soc Cogn Affect Neurosci (2008) 3:55-61. doi:10.1093/scan/ nsm038

87. Lazar SW, Kerr CE, Wasserman RH, Gray JR, Greve DN, Treadway MT, et al. Meditation experience is associated with increased cortical thickness. Neuroreport (2005) 16:1893-7. doi:10.1097/01.wnr. 0000186598.66243.19

88. Brefczynski-Lewis JA, Lutz A, Schaefer HS, Levinson DB, Davidson RJ. Neural correlates of attentional expertise in long-term meditation practitioners. Proc Natl Acad Sci U S A (2007) 104:11483-8. doi:10.1073/pnas.0606552104

89. Cahn BR, Polich J. Meditation states and traits: EEG, ERP, and neuroimaging studies. Psychol Bull (2006) 132:180-211. doi:10.1037/ 0033-2909.132.2.180

90. Dickenson J, Berkman ET, Arch J, Lieberman MD. Neural correlates of focused attention during a brief mindfulness induction. Soc $\operatorname{Cog} n$ Affect Neurosci (2013) 8:40-7. doi: 10.1093/scan/nss030

91. Farb NA, Segal ZV, Mayberg H, Bean J, McKeon D, Fatima Z, et al. Attending to the present: mindfulness meditation reveals distinct neural modes of selfreference. Soc Cogn Affect Neurosci (2007) 2:313-22. doi:10. 1093/scan/nsm030

92. Ives-Deliperi VL, Solms M, Meintjes EM. The neural substrates of mindfulness: an fMRI investigation. Soc Neurosci (2011) 6:231-42. doi:10.1080/17470919. 2010.513495

93. Zeidan F, Martucci KT, Kraft RA, Gordon NS, McHaffie JG, Coghill RC. Brain mechanisms supporting the modulation of pain by mindfulness meditation. $\mathrm{J} \mathrm{Neu}$ rosci (2011) 31:5540-8. doi:10. 1523/JNEUROSCI.5791-10.2011

94. Lutz A, McFarlin DR, Perlman DM, Salomons TV, Davidson RJ. Altered anterior insula activation during anticipation and experience of painful stimuli in expert meditators. Neuroimage (2012) 64C:538-46. doi:10.1016/j. neuroimage.2012.09.030

95. Allen M, Dietz M, Blair KS, van Beek M, Rees G, Vestergaard-Poulsen $\mathrm{P}$, et al. Cognitive-affective neural plasticity following active-controlled mindfulness intervention. $J \mathrm{Neu}$ rosci (2012) 32:15601-10. doi:10. 1523/JNEUROSCI.2957-12.2012

96. Farb NA, Segal ZV, Anderson AK. Mindfulness meditation training alters cortical representations of interoceptive attention. Soc Cogn Affect Neurosci (2012) 8:15-26. doi:10.1093/scan/nss066

97. Witkiewitz K, Lustyk MK, Bowen S. Retraining the addicted brain: a review of hypothesized neurobiological mechanisms of mindfulness-based relapse prevention. Psychol Addict Behav (2013) 27:351-65. doi:10.1037/a0029258

98. Khanna S, Greeson JM. A narrative review of yoga and mindfulness as complementary therapies for addiction. Complement Ther Med (2013) 21:244-52. doi: 10.1016/j.ctim.2013.01.008

99. Zgierska A, Rabago D, Zuelsdorff M, Coe C, Miller M, Fleming M. Mindfulness meditation for alcohol relapse prevention: a feasibility pilot study. $J$ Addict Med (2008) 2:165-73. doi:10. 1097/ADM.0b013e31816f8546

100. Elwafi HM, Witkiewitz K, Mallik S, Thornhill TAT, Brewer JA. Mindfulness training for smoking cessation: moderation of the relationship between craving and cigarette use. Drug Alcohol Depend (2013) 130:222-9. doi:10.1016/j. drugalcdep.2012.11.015

101. Witkiewitz K, Bowen S. Depression, craving, and substance use following a randomized trial of mindfulness-based relapse prevention. J Consult Clin Psychol (2010) 78:362-74. doi:10.1037/a0019172

102. Brewer JA, Bowen S, Smith JT, Marlatt GA, Potenza MN Mindfulness-based treatments for co-occurring depression and substance use disorders: what can we learn from the brain? Addiction (2010) 105:1698-706. doi:10. 1111/j.1360-0443.2009.02890.x

103. Garland EL, Boettiger CA, Gaylord S, Chanon VW, Howard MO. Mindfulness is inversely associated with alcohol attentional bias among recovering alcoholdependent adults. Cognit Ther Res (2012) 36:441-50. doi:10.1007/ s10608-011-9378-7

104. Westbrook C, Creswell JD, Tabibnia G, Julson E, Kober H, Tindle HA. Mindful attention reduces neural and self-reported cue-induced craving in smokers. Soc Cogn Affect Neurosci (2013) 8:73-84. doi:10.1093/scan/nsr076

105. Garland EL I, Franken H, Howard MO. Cue-elicited heart rate variability and attentional bias predict alcohol relapse following treatment. Psychopharmacology (Berl) (2012) 222:17-26. doi:10.1007/s00213-011-2618-4

106. Williamson JW, Fadel PJ, Mitchell $J \mathrm{H}$. New insights into central cardiovascular control during exercise in humans: a central command update. Exp Physiol (2006) 91:51-8. doi:10.1113/expphysiol. 2005.032037

107. Marcora SM. Do we really need a central governor to explain brain regulation of exercise performance? Eur J Appl Physiol (2008) 104:929-31. doi:10.1007/s00421008-0818-3

108. Noakes TD, Peltonen JE, Rusko HK. Evidence that a central governor regulates exercise performance during acute hypoxia and hyperoxia. J Exp Biol (2001) 204:3225-34.

109. Williamson JW, Nobrega AC, McColl R, Mathews D, Winchester P, Friberg L, et al. Activation of the insular cortex during dynamic exercise in humans. J Physiol (1997) 503(Pt 2):277-83. doi:10. 1111/j.1469-7793.1997.277bh.x

110. Williamson JW, McColl R, Mathews D, Mitchell JH, Raven PB, Morgan WP. Brain activation by central command during actual and imagined handgrip under hypnosis. J Appl Physiol (2002) 92:1317-24. doi:10.1152/ japplphysiol.00939.2001

111. Williamson JW, McColl R, Mathews D, Ginsburg M, Mitchell JH. Activation of the insular cortex is affected by the intensity of exercise. J Appl Physiol (1999) 87:1213-9.

112. Borg G, Dahlstrom H. A case study of perceived exertion during a work test. Acta Soc Med Ups (1962) 67:91-3.

113. St Clair GA, Noakes TD. Evidence for complex system integration and dynamic neural regulation of skeletal muscle recruitment during exercise in humans. BrJ Sports Med (2004) 38:797-806. doi:10.1136/bjsm.2003.009852

114. Tucker R. The anticipatory regulation of performance: the physiological basis for pacing strategies and the development of a perception-based model for exercise performance. Br J Sports Med (2009) 43:392-400. doi:10.1136/ bjsm.2008.050799

115. Hampson DB, St Clair Gibson A, Lambert MI, Noakes TD. The influence of sensory cues on the perception of exertion during exercise and central regulation 
of exercise performance. Sports Med (2001) 31:935-52. doi:10. 2165/00007256-200131130-00004

116. Marcora S. Counterpoint: afferent feedback from fatigued locomotor muscles is not an important determinant of endurance exercise performance. J Appl Physiol (2010) 108:454-6. doi:10.1152/ japplphysiol.00976.2009a

117. Marcora SM, Staiano W, Manning V. Mental fatigue impairs physical performance in humans. J Appl Physiol (2009) 106:857-64. doi:10. 1152/japplphysiol.91324.2008

118. Lynch WJ, Peterson AB, Sanchez V, Abel J, Smith MA. Exercise as a novel treatment for drug addiction: a neurobiological and stage-dependent hypothesis. Neurosci Biobehav Rev (2013) 37:162244. doi:10.1016/j.neubiorev.2013. 06.011

119. Ussher M, Sampuran AK, Doshi R, West R, Drummond DC. Acute effect of a brief bout of exercise on alcohol urges. Addiction (2004) 99:1542-7. doi:10.1111/j. 1360-0443.2004.00919.x

120. Janse Van Rensburg K, Taylor A, Benattayallah A, Hodgson $\mathrm{T}$. The effects of exercise on cigarette cravings and brain activation in response to smokingrelated images. Psychopharmacology (Berl) (2012) 221:659-66. doi: 10.1007/s00213-011-2610-z

121. Roberts V, Maddison R, Simpson C, Bullen C, Prapavessis H. The acute effects of exercise on cigarette cravings, withdrawal symptoms, affect, and smoking behaviour: systematic review update and metaanalysis. Psychopharmacology (Berl) (2012) 222:1-15. doi:10.1007/s00213-012-2731-z

122. Buchowski MS, Meade NN, Charboneau E, Park S, Dietrich MS, Cowan RL, et al. Aerobic exercise training reduces cannabis craving and use in non-treatment seeking cannabis-dependent adults. PLoS ONE (2011) 6:e17465. doi:10. 1371/journal.pone. 0017465

123. Janse Van Rensburg K, Taylor A, Hodgson T, Benattayallah A. Acute exercise modulates cigarette cravings and brain activation in response to smokingrelated images: an fMRI study. Psychopharmacology (Berl) (2009) 203:589-98. doi:10.1007/s00213008-1405-3
124. Garavan H, Weierstall K. The neurobiology of reward and cognitive control systems and their role in incentivizing health behavior. Prev Med (2012) 55(Suppl):S17-23. doi:10.1016/j.ypmed.2012.05.018

125. Salo R, Ursu S, Buonocore MH, Leamon MH, Carter C. Impaired prefrontal cortical function and disrupted adaptive cognitive control in methamphetamine abusers: a functional magnetic resonance imaging study. Biol Psychiatry (2009) 65:706-9. doi:10.1016/j. biopsych.2008.11.026

126. Winkielman P, Niedenthal P, Oberman L. Embodied perspective on emotion-cognition interactions. In: Pineda J editor. Mirror Neuron Systems. New York, NY: Humana Press (2009). p. 235-57.

127. Paulus MP, Flagan T, Simmons AN, Gillis K, Kotturi S, Thom $\mathrm{N}$, et al. Subjecting elite athletes to inspiratory breathing load reveals behavioral and neural signatures of optimal performers in extreme environments. PLoS ONE (2012) 7:e29394. doi:10. 1371/journal.pone.0029394
Conflict of Interest Statement: The authors declare that the research was conducted in the absence of any commercial or financial relationships that could be construed as a potential conflict of interest.

Received: 01 August 2013; accepted: 03 October 2013; published online: 18 October 2013.

Citation: Paulus MP, Stewart JL and Haase L (2013) Treatment approaches for interoceptive dysfunctions in drug addiction. Front. Psychiatry 4:137. doi: 10.3389/fpsyt.2013.00137

This article was submitted to Addictive Disorders and Behavioral Dyscontrol, a section of the journal Frontiers in Psychiatry.

Copyright $\odot 2013$ Paulus, Stewart and Haase. This is an open-access article distributed under the terms of the Creative Commons Attribution License (CC BY).

The use, distribution or reproduction in other forums is permitted, provided the original author(s) or licensor are credited and that the original publication in this journal is cited, in accordance with accepted academic practice. No use, distribution or reproduction is permitted which does not comply with these terms. 